\title{
QUITOSANA: DERIVADOS HIDROSSOLÚVEIS, APLICAÇÕES FARMACÊUTICAS E AVANÇOS
}

\author{
Hélio S. R. Costa Silva*, Kátia S. C. R. dos Santos e Elizabeth I. Ferreira \\ Departamento de Farmácia, Faculdade de Ciências Farmacêuticas, Universidade de São Paulo, \\ Av. Prof. Lineu Prestes 580, 05508-900 São Paulo - SP, Brasil
}

Recebido em 15/3/05; aceito em 3/8/05; publicado na web em 14/3/06

\begin{abstract}
CHITOSAN: HYDROSSOLUBLE DERIVATIVES, PHARMACEUTICAL APPLICATIONS AND RECENT ADVANCES. Chitin and chitosan are copolymers build from $N$-acetyl- $D$-glucosamine and $D$-glucosamine. The former is widely found in nature and yields the latter on deacetylation. The copolymers are being used for several purposes. Since 1977, when the First International Conference on Chitin and Chitosan was held in Boston, USA, the interest on chitin and chitosan has remarkably increased. This review emphasizes pharmaceutical applications of chitosan and its derivatives, and presents recent advances. Some therapeutical applications of these polymers are also discussed.
\end{abstract}

Keywords: chitosan; hydrossoluble derivatives; pharmaceutical applications.

\section{INTRODUÇÃO}

Quitina e quitosana são copolímeros constituídos por unidades $N$ acetil- $D$-glicosamina e $D$-glicosamina em proporções variáveis, sendo que o primeiro tipo dessas unidades predomina no caso de quitina, enquanto quitosana é composta predominantemente, por unidades $D$ glicosamina ${ }^{1}$. A quitina é o segundo polissacarídeo mais abundante na natureza depois da celulose, sendo o principal componente do exoesqueleto de crustáceos e insetos; sua presença ocorre também em nematóides e parede celular de fungos e leveduras ${ }^{1}$. A quitosana pode ser obtida a partir da quitina por meio da desacetilação com álcalis, podendo também estar naturalmente presente em alguns fungos, como aqueles pertecentes aos gêneros Mucor e Zygomicetes ${ }^{2}$. De acordo com o grau médio de acetilação (GA), parâmetro empregado para caracterizar o conteudo médio de unidades $N$-acetil- $D$-glicosamina de quitina e quitosana, podem-se obter diversas quitosanas variando-se, assim, suas propriedades físico-químicas, como solubilidade, $\mathrm{pKa}$ e viscosidade ${ }^{3}$. Geralmente, é difícil de se obter quitosana com elevado grau de desacetilação, pois, à medida que este aumenta, a possibilidade de degradação do polímero também aumenta ${ }^{4}$. A Figura 1 representa as estruturas químicas parciais da quitina e quitosana.

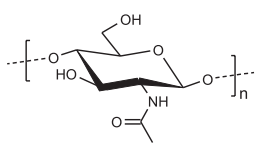

quitina

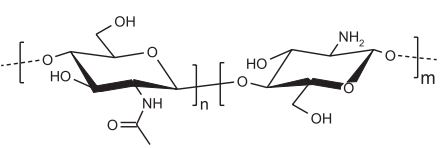

quitosana
Figura 1. Estruturas da quitina e quitosana

O emprego de quitina e quitosana e a pesquisa por novas aplicações têm aumentado exponencialmente em diversas áreas, como na agricultura e indústria de alimentos, mas, especialmente, na indústria farmacêutica, no desenvolvimento de $\operatorname{cosméticos}^{5-12}$ e biomateriais, tais como géis, filmes e membranas poliméricas ${ }^{13-17}$.

De acordo com Khor ${ }^{18}$, um aspecto importante na utilização de quitosana diz respeito à sua produção a partir da quitina. Esta deve ser realizada de forma adequada, de maneira que garanta, ao final do processo, a obtenção de quitosana com alto grau de pureza,

*e-mail: helio@doctor.com sobretudo isenta de contaminantes, como proteínas, endotoxinas e metais tóxicos. Neste âmbito, é válido ressaltar que o polímero obtido deve ser caracterizado adequadamente quanto à massa molar, grau de acetilação e distribuição deste grupo ao longo da cadeia polimérica. Estas características podem influenciar na biodegradabilidade do mesmo, principalmente na acessibilidade enzimática, influenciando a hidrólise do polissacarídeo.

\section{DERIVADOS HIDROSSOLÚVEIS DE QUITOSANA}

Algumas aplicações farmacêuticas da quitosana são limitadas por problemas de hidrossolubilidade, uma vez que esta é insolúvel em água em meio neutro, condição em que enzimas fisiológicas exercem sua atividade ${ }^{1}$. Partindo do princípio que derivados de quitina e quitosana podem ser preparados a fim de se melhorar sua solubilidade em água, as aplicações destes polímeros podem aumentar significativamente.

Desde a descoberta da molécula da quitosana, há cerca de 150 anos, sempre se acreditou que este polímero fosse insolúvel em meio alcalino. Porém, Muzzarelli e colaboradores ${ }^{19}$, de forma inovadora, conseguiram desenvolver sistema em que pode existir quitosana solúvel, mesmo em pH 10. Esta solubilidade é alcançada devido à formação do íon carbamato após adição de $\mathrm{NH}_{4} \mathrm{HCO}_{3}$, de acordo com a Equação 1:

$$
\text { CHIT-NH }{ }_{2}+\mathrm{NH}_{4} \mathrm{HCO}_{3} \Leftrightarrow \text { CHIT-NHCO }{ }_{2}^{-} \mathrm{NH}_{4}^{+}+\mathrm{H}_{2} \mathrm{O}
$$

A forma solúvel de carbamato de amônio tem sido utilizada satisfatoriamente na obtenção de microesferas de quitosana por "spray drying", visando sua utilização como transportadores de fármacos ${ }^{20}$.

Modificações químicas na molécula de quitina, em geral, são dificultadas em razão de que este polissacarídeo possui estrutura altamente cristalina, com fortes interações entre hidrogênios intra e intermoleculares ${ }^{21}$. Geralmente, em condições heterogêneas, a reatividade deste polissacarídeo tende a aumentar com o decréscimo do grau de cristalinidade e a reação pode se processar mais rapidamente em regiões amorfas que em regiões cristalinas. Além disto, os produtos obtidos em condições heterogêneas podem ter difícil controle do grau de substituição, bem como da solubilidade e de outras propriedades ${ }^{21}$. 
Jia e colaboradores ${ }^{22}$ relataram a produção de sais de amônio quartenário de quitosana solúveis em água dotados de atividade antibacteriana. A produção do sal ocorre quando o grupo amino da quitosana reage com um aldeído para formar uma imina, ou base de Schiff. Este intermediário reage com iodeto de metila para formar o sal quaternário da quitosana. Evidenciou-se que a massa molecular da quitosana influencia a solubilidade e a atividade antibacteriana dos derivados. Quitosana de baixa massa molecular resultou em derivados dotados de maior solubilidade. De forma oposta, o poder bactericida aumentou com o aumento da massa molecular da quitosana.

Le Dung e colaboradores ${ }^{4}$ obtiveram derivados hidrossolúveis em condições homogêneas, utilizando quitosanas com baixo grau de acetilação (12,5 e 11\%). Os derivados obtidos, sais quartenários de quitosana e $N$-carboximetilquitosana, mostraram-se solúveis em toda a faixa de $\mathrm{pH}$. A $\mathrm{N}$-carboximetilquitosana é obtida em duas etapas, em que, primeiramente, se dissolve a quitosana em água, na presença de ácido glioxílico, e, em seguida, se adiciona o agente redutor (boroidreto de sódio). A formação do derivado dissubstituído é favorecida em relação à do monossubstituído, chegando a atingir $90 \%$ do produto formado.

Xie e colaboradores ${ }^{23}$ conseguiram inserir o ácido maléico em hidroxipropilquitosana e carboximetilquitosana e produzir derivados hidrossolúveis. Esses derivados da quitosana (GA $=3 \%$ e $\mathrm{MM}$ $=880.000 \mathrm{Da}$ ) são dotados de propriedades antioxidantes.

Baumann e Faust ${ }^{24}$ descreveram a síntese de derivados de quitosana solúveis em água, como $O$-sulfo, $N$-sulfo e $N$-carboximetilquitosana. Estes pesquisadores observaram que a quitosana de baixa massa molar produz derivados com maior solubilidade e a substituição seletiva pode ocorrer mais facilmente. Os derivados $N$-sulfo e $N$-carboximetilquitosana foram obtidos de forma seqüencial. Inicialmente, procedeu-se à hidrolise parcial da quitosana $(\mathrm{MM}=150.000 \mathrm{Da}, \mathrm{GA}=$ $28 \%$ ) com $\mathrm{HCl}$. A hidrólise é condição indispensável para garantir as substituições de forma seletiva. De acordo com os autores, este fenômeno acontece pelo fato de quitosana com baixa massa molar ser dotada de melhor solubilidade em água, conferindo caráter homogêneo e menor viscosidade ao sistema, auxiliando, assim, a ocorrência da reação de forma seletiva. A $N$-acetilação da quitosana obtida após hidrólise $(\mathrm{MM}=29.000 \mathrm{Da}, \mathrm{GA}=14 \%)$ com anidrido acético resulta em derivado solúvel com grau de desacetilação $55 \%$.

Sashiwa e Shigemasa ${ }^{25}$ propuseram a obtenção de diversos derivados de quitosana hidrossolúveis. Estes incluem derivados do tipo $\mathrm{N}$ alquil e $N$-acil-quitosana, como succinilquitosana e maleilquitosana. A obtenção dos derivados $N$-acilados, que parte de quitosana $88 \%$ desacetilada, dá-se em presença de anidridos cíclicos. Os derivados obtidos não são solúveis em toda a faixa de $\mathrm{pH}$ : cada um possui zona de solubilidade particular. Succinilquitosana mostrou duas zonas de solubilidade, nas faixas de $\mathrm{pH}$ 1,0-3,5 e 7,0-13. A solubilidade em condições ácidas é explicada pela protonação do grupo amínico livre, característico na quitosana in natura, que passa de $\mathrm{NH}_{2}$ a $\mathrm{NH}_{3}^{+}$, enquanto que em meio alcalino, a hidrossolubilidade se deve à formação do carboxilato, a partir do grupo carboxílico introduzido.

A obtenção de quitosana $N$-metilenofosfônica, derivado hidrossolúvel, também é descrita na literatura ${ }^{26-28}$. Sua obtenção foi realizada utilizando-se ácido fosfórico e formaldeído e o derivado obtido é, atualmente, objeto de patente.

Hirano e colaboradores ${ }^{29-31}$ sintetizaram derivados de quitosana $N$-carboxiacilados, utilizando anidridos em ácido acético e metanol, e conseguiram obter derivados hidrossolúveis. Após a síntese dos derivados acilados, realizou-se estudo da cisão da ligação formada usando enzimas (quitinases e lisozimas). Foi verificado que a mesma pode sofrer hidrólise. Pizza e colaboradores ${ }^{32}$ evidenciaram que a hidrólise de quitosana via quitosanases é função de $\mathrm{pH}$ e tempe- ratura, sendo $\mathrm{pH} 5,8$ e $54{ }^{\circ} \mathrm{C}$ condições ideais para hidrólise da quitosana avaliada.

Muzzarelli e colaboradores ${ }^{33}$ relataram, de forma pioneira, a produção de $N$-carboxibutilquitosana mediante utilização do ácido levulínico. Observaram que o tamanho da cadeia do ácido levulínico é ideal para reduzir as interações intra e intermoleculares na quitosana e, assim, aumentar sua solubilidade.

Rinaudo e colaboradores ${ }^{34}$ também descreveram a obtenção de $\mathrm{N}$-carboxibutilquitosana e 5-metilpirrolidinona quitosana solúvel em água. A $N$-carboxibutilquitosana foi produzida utilizando-se quitosana $\mathrm{A}(\mathrm{GA}=2 \%$ e $\mathrm{Mv}=100.000 \mathrm{~g} / \mathrm{mol})$, enquanto que a 5metilpirrolidinona foi obtida a partir de quitosana $\mathrm{B}(\mathrm{GA}=12 \% \mathrm{e}$ $\mathrm{Mv}=190.000 \mathrm{~g} / \mathrm{mol})$. Como agentes redutores, empregaram o boroidreto de sódio para obtenção do derivado linear e o cianoboroidreto de sódio para obtenção do derivado cíclico. Parâmetro importante para derivatizar a quitosana é o conteúdo de ácido levulínico, que deve estar em excesso para promover a dissolução da mesma e formar a cetamina. Excesso do agente redutor também é necessário, porém, se não houver controle, pode haver degradação do polímero. A solubilidade do polímero obtido, em meio ácido, neutro ou básico, é explicada pelo caráter anfotérico adquirido após a reação.

Costa Silva e colaboradores ${ }^{35}$ e dos Santos e colaboradores ${ }^{36}$ descreveram a obtenção da carboxibutilquitosana com grau de substituição superior ao descrito na literatura. Nestes trabalhos, a quitosana foi primeiramente purificada e caracterizada de acordo com a metodologia proposta por Canella e $\mathrm{Garcia}^{37}$.

Dos Santos e colaboradores ${ }^{38}$ utilizaram, de forma inovadora, metodologia para otimização da síntese da carboxibutilquitosana por planejamento fatorial $3^{2}$. Esse estudo constatou que o aumento da concentração molar de ácido levulínico favorece a formação da $N$-carboxibutilquitosana, enquanto que o aumento da concentração do agente redutor favorece a ciclização do grupo carboxílico para formação da 5-metilpirrolidinona quitosana. A Figura 2 ilustra importantes derivados hidrofílicos encontrados na literatura.
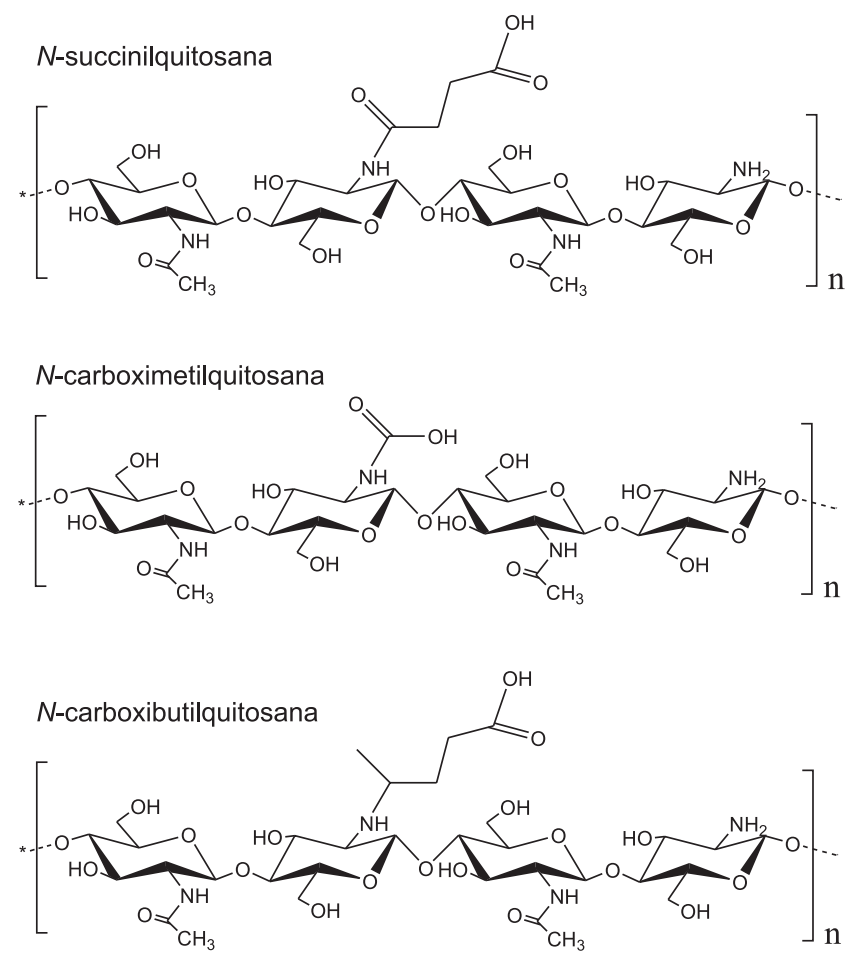

Figura 2. Derivados hidrofílicos de quitosana 


\section{PROPRIEDADES BIOLÓGICAS}

\section{Atividade antimicrobiana}

Dentre as inúmeras características que distinguem quitina e quitosana dos demais polissacarídeos destaca-se a atividade antimicrobiana. Esses polímeros provocam a inibição do crescimento de microrganismos, como E. coli, Fusarium, Alternaria, Helminthosporium $^{39}$, S. epidermidis, P. aeruginosa, S. pyogenes, $K$. pneumoniae, S. aureus, S. faecalis ${ }^{40}$, Shigella dysenteriae, Aeromonas hydrophila, Salmonella typhimurium, Bacillus cereus, Coliforms, Vibrio ${ }^{3}$, Agrobacterium tumefaciens, Corynebacterium michiganence, Erwinia sp., Micrococcus luteus, Pseudomonas fluorescens, Xanthomonas campestris, Botrytis cinerea, Fusarium oxysporum, Drechslera sorokiniana, Micronectriella nivalis, Procularia oryzae, Rhizoctonia solani, Tricophyton equinum ${ }^{41} \mathrm{e}$ Candida ${ }^{42}$. Alguns pesquisadores explicam a atividade antimicrobiana da quitosana por seus grupos amínicos que, uma vez em contato com os fluidos fisiológicos, provavelmente são protonados e se ligam a grupos aniônicos desses microrganismos, resultando na aglutinação das células microbianas e inibição do crescimento $^{39,40}$.

Estudos mais recentes, entretanto, revelam que o mecanismo da atividade antimicrobiana da quitosana está intimamente relacionado às propriedades físico-químicas do polímero e às características da membrana do microrganismo. Micrografias eletrônicas realizadas por Lifeng e colaboradores ${ }^{43}$ de $S$. aureus (bactéria gram-positiva) e E. coli (bactéria gram-negativa) na presença de quitosana mostram que a membrana do $S$. aureus foi enfraquecida ou até mesmo fragmentada, enquanto o citoplasma da $E$. coli foi concentrado e o interstício da célula, ampliado. Zheng e Zhu ${ }^{44}$ demonstraram que a atividade antimicrobiana contra bactérias gram-positivas aumenta quanto maior a massa molecular do polímero, enquanto que, para bactérias gram-negativas, quanto menor a massa molecular da quitosana, maior a atividade antimicrobiana. Esses resultados sugerem que os efeitos da quitosana são distintos nos dois tipos de bactérias: no caso das gram-positivas, a hipótese é que quitosana de alta massa molecular forma películas ao redor da célula que acabam por inibir a absorção de nutrientes, enquanto que quitosana de baixa massa molecular penetra mais facilmente em bactérias gram-negativas, causando distúrbios no metabolismo desses microrganismos.

\section{Efeito coagulante}

Quitina e quitosana desempenham, ainda, importante papel na hemostase ${ }^{3,40}$, porém de maneira independente ao sistema clássico da cascata de coagulação ${ }^{45}$. Okamoto e colaboradores ${ }^{46}$ mostraram que esses polímeros reduzem o tempo de coagulação sanguínea de forma dose-dependente, sendo a quitosana (tempo de coagulação sanguínea de 3,7 min) mais eficaz que a quitina (tempo de coagulação sanguínea de 4,7 min) na coagulação sanguínea sob a mesma concentração de $0,1 \mathrm{mg} / \mathrm{mL}$ (tempo de coagulação sanguínea de 12 min para o controle), embora a quitina tenha maior capacidade em agregar plaquetas $(61,2 \%)$ que a quitosana $(27,9 \%)$. $\mathrm{O}$ fato de a quitosana ser mais eficaz na coagulação sanguínea, mesmo quando a quitina tem maior poder de agregação plaquetária, é atribuído à sua capacidade em agregar, também, os eritrócitos ${ }^{45,46}$ devido à interação das cargas positivas dos grupos amínicos livres da quitosana com as cargas negativas de receptores dos eritrócitos contendo resíduos de ácido neuramínico ${ }^{3}$ e murâmico ${ }^{45}$. A ação da quitina e quitosana sobre as plaquetas produz mais um efeito benéfico, que é a liberação de fator de crescimento derivado de plaquetasAB (PDGF-AB) e fator de transformação do crescimento- $\beta_{1}$ (TGF- $\beta_{1}$ ), provavelmente pelo dano causado às membranas plaquetárias pela forte agregação induzida, principalmente, pela quitosana ${ }^{46}$. PDGF-AB e TGF- $\beta_{1}$ são citocinas liberadas pelas plaquetas, que desempenham importante papel no processo de cicatrização.

\section{Efeito analgésico}

É atribuída à quitina e quitosana potente ação analgésica tópica, também. Estudos realizados por Okamoto ${ }^{47}$ sugerem que o principal efeito analgésico da quitosana é decorrente da captura de hidrogênios ácidos liberados no local da inflamação pela ionização do grupo amínico a $\mathrm{NH}_{3}^{+}$. A bradicinina, mediador químico liberado pelo cininogênio plasmático e outras citocinas, como Fator de Necrose Tumoral $\alpha$ (FNT $\alpha$ ) e as Interleucinas 1 (IL-1) e 8 (IL-8), parece ser particularmente importante para a produção da dor no local inflamado ${ }^{48}$. A quitosana teria a propriedade de absorver a bradicinina liberada no sítio da inflamação e a quitina, capacidade de absorção quase três vezes maior que esta.

\section{Aceleração da cicatrização}

A propriedade imunomoduladora da quitosana (Figura 3) é devida à sua capacidade de ativar quase que exclusivamente o macrófago $0^{40}$ e explica não somente seu papel na aceleração da cicratização de lesões, mas também a biodegradabilidade desse polímero no organismo. Os macrófagos, ativados pelos oligômeros de quitina e quitosana de baixa massa molecular, liberam interleucina-1, que estimula a proliferação de fibroblastos e influencia a estrutura do colágeno. Liberam, também, $\mathrm{N}$-acetilglicosaminidase, que hidrolisa a quitosana a monômeros de $\mathrm{N}$ acetilglicosamina e glicosamina, unidades de açúcares necessárias à biossíntese do ácido hialurônico e outros componentes da matriz extracelular pelos fibroblastos ${ }^{49,50}$. Promovem a migração de neutrófilos, facilitando a resolução da resposta inflamatória. As atividades bactericidas e bacteriostáticas sugerem que estes polímeros podem prevenir infecções, se aplicados diretamente no local da lesão ${ }^{42}$. A quitosana é excelente umectante e adere melhor que ácido hialurônico, além de ser economicamente mais viável ${ }^{51}$.

Em culturas de células tratadas com quitina e seus derivados, verificou-se o aumento da atividade da lisozima extracelular, o que estimula a formação de tecido conjuntivo ${ }^{39} . N$-acetilglicosamina é

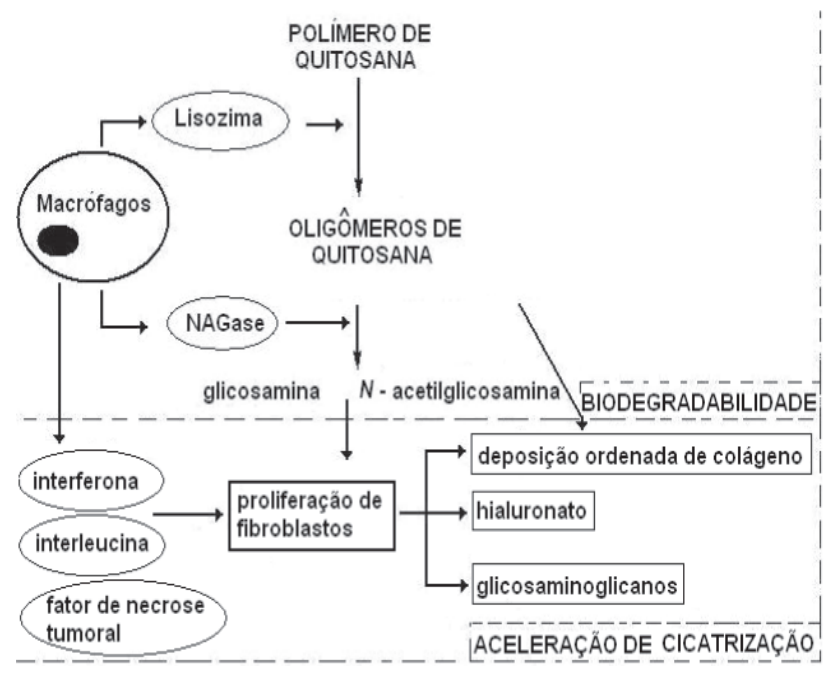

Figura 3. Mecanismo imunomodulador da quitosana, que resulta na biodegradabilidade do polímero e aceleração do processo de cicatrização. Adaptado das refs. 49 e 50 
o maior componente do epitélio e sua presença é essencial na reparação tecidual das feridas. Quitina e quitosana são facilmente despolimerizadas pela lisozima, presente naturalmente no fluido da lesão, e funcionam como fontes de liberação retardada de monômeros $N$-acetilglicosamina no processo de cicatrização $0^{3,39,40}$. Além disso, feridas tratadas com quitosana mostraram menor grau de fibroplasia ${ }^{3,51}$, favorecendo a reepitelização com formação de cicatriz lisa ${ }^{52}$. A sua despolimerização pela lisozima também pode ser aproveitada no desenvolvimento de sistemas bioerosíveis para a liberação de fármacos ${ }^{51}$. $\mathrm{O}$ fato de a quitosana ser alvo de ataque da lisozima e da NAGase gerando, ao final do processo de despolimerização, $N$-acetilglicosamina e glicosamina, dois açúcares envolvidos na reepitelização, explica a propriedade biodegradável desse polímero. Essa característica, associada à baixa toxicidade, faz da quitosana polímero biocompatível.

Estas propriedades estão sendo exploradas no desenvolvimento de biomateriais comerciáveis para tratamento de feridas ${ }^{39}$. No Japão, já se encontra disponível pele artificial de quitina, a Besquitin $\mathrm{W}^{\circledR}$, que pode ser aplicada em casos de queimaduras superficiais, profundas e de terceiro grau, além de lesões traumáticas e abrasivas, promovendo hemostasia, analgesia e aceleração da epitelização ${ }^{52}$.

\section{Tratamento de osteoartrite}

A quitosana também tem sido experimentada no tratamento da osteoartrite, cuja farmacoterapia é realizada à base de antiinflamatórios, como paracetamol, inibidores da cicloxigenase 2 (COX2 ), esteróides intra-articulares, vitaminas e visco-suplementos ${ }^{53}$. No entanto, este arsenal terapêutico se destina, apenas, a aliviar os sintomas desta enfermidade, não resolvendo o principal problema desta patologia, que consiste na degeneração celular em nível de tecido conjuntivo $^{54}$. Por esta razão, tem surgido grande interesse no tratamento desta enfermidade com $\mathrm{N}$-acetilglicosamina e glicosamina, monômeros de quitina e quitosana, respectivamente. Glicosamina estimula a biossíntese de peptideoglicanos e estes auxiliam na manutenção estrutural do tecido conjuntivo, agindo como estabilizadores de membrana, diminuindo a geração de radicais superóxidos e inibindo enzimas lisossômicas ${ }^{55}$. No entanto, a administração oral de glicosamina apresenta problema de biodisponibilidade, pois a mesma sofre rápida eliminação pré-sistêmica no fígado, sendo convertida a dióxido de carbono, água e uréia. Esta biotransformação diminui em 5 vezes a biodisponibilidade relativa da glicosamina, quando comparada à via endovenosa ${ }^{56}$.

Estudos têm demonstrado que quitosana é capaz de promover liberação sustentada de glicosamina. Ingestão oral (1 g/dia) de $N$ acetilglicosamina ou quitosana aumentou a concentração sérica de glicosamina. No entanto, apenas quitosana foi capaz de manter este aumento $48 \mathrm{~h}$ após a ingestão oral ${ }^{57}$. Setnikat e colaboradores $^{58}$ também encontraram resultados semelhantes, corroborando, desta forma, a utilização de quitosana como fonte de glicosamina e, por conseguinte, sua adequação ao tratamento de osteoartrites.

Evidências experimentais de vários laboratórios indicam que quitosana administrada por via oral é parcialmente digerida e absorvida no trato gastrintestinal. Esta digestão deve-se à ação de ácido clorídrico no estômago e enzimas inespecíficas presentes na saliva e suco gástrico. No instestino, outras enzimas da flora normal também são capazes de digerir quitosana ${ }^{55}$.

\section{Efeito hipocolesterolêmico e hipolipidêmico}

O uso interno da quitosana, por via oral, promove a redução dos níveis de colesterol e triglicerídeos plasmáticos devido à sua capacidade de se ligar aos lipídeos da dieta, interferindo na absorção intesti- nal dessas gorduras ${ }^{41,42}$. O primeiro relato da capacidade de quitosana em reduzir colesterol foi provalvelmente descrito por Sugano e colaboradores $^{59}$. Estes pesquisadores demonstraram que dieta contendo $5 \%$ de quitosana foi capaz de reduzir o nível de colesterol sérico à metade em ratos. Este efeito foi confirmado pouco depois por Kobayashi e colaboradores ${ }^{60}$. Estes últimos encontraram percentual de redução em torno de $27 \%$ para colesterol hepático e $26 \%$ para colesterol sérico, quando ratos foram alimentados com dieta em que havia $4 \%$ de quitosana. Desde então, têm sido inúmeros os relatos que atestam a capacidade hipocolesterolêmica de quitosana em animais. O colesterol sérico foi reduzido em 52\%, quando animais foram alimentados com quitosana e avaliados por 20 semanas. De forma surpreendente, os animais que ingeriram quitosana apresentaram ganho de peso em torno de $65 \%$, se comparados ao grupo controle ${ }^{61}$. Em outro estudo ${ }^{62}$, quando quitosana foi administrada durante 2 semanas, o colesterol sérico total sofreu redução significativa. $\mathrm{O}$ nível diminuiu $77 \%$ em 7 dias, e 54\% em 14, porém, voltou ao valor inicial depois de 28 dias. Quitina e celulose não apresentaram atividade hipocolesterolêmica. As propriedades hipoglicêmica e hipolipidêmica da quitosana também foram demonstradas pelo estudo em ratos normais e obesos, alguns com hiperinsulinemia e outros, hipoinsulinemia. Em nenhum caso se observou alteração de peso. Os animais, exceto aqueles com hiperinsulinemia, apresentaram decréscimo significativo no valor da glicose sanguínea, do colesterol e dos triglicerídeos. Esta avaliação durou 4 semanas, com administração de quitosana a $5 \%{ }^{63}$. De forma segura, pode-se assumir que a atividade hipocolesterolêmica de quitosana em animais está bem consolidada na literatura ${ }^{55}$.

$\mathrm{O}$ uso de quitosana como hipocolesterolêmico em humanos foi primeiramente documentado por Maezaki e colaboradores ${ }^{64}$. Neste estudo, adultos do sexo masculino foram alimentados com biscoitos à base de quitosana por 2 semanas. Aqueles que utilizaram a dose de $3 \mathrm{~g} /$ dia durante 1 semana e 1,6 g/dia durante 2 apresentaram redução de $6 \%$ do colesterol total. Acredita-se que o efeito hipocolesterolêmico de quitosana seja dose dependente, pois Pittler e colaboradores ${ }^{65}$ realizaram estudo com 28 dias de duração, sendo a dose diária de quitosana em torno de $0,6 \mathrm{~g} /$ dia e nenhuma redução significativa do nível de colesterol foi observada. Gallaher ${ }^{66}$ acredita que o insucesso deste trabalho ocorreu, provavelmente, devido à baixa dose utilizada. Em outro estudo ${ }^{67}$, mulheres obesas utilizando 1,2 g/dia de quitosana microcristalina durante 8 semanas mostraram significativa redução de LDL plasmático, sem, no entanto, apresentarem alteração em nível de colesterol sérico.

Bokura e Kobayashi ${ }^{68}$ relataram que mulheres com moderada hipercolesterolemia podem responder de forma satisfatória à dose de $1,2 \mathrm{~g}$ de quitosana/dia, apresentando, ao final da avaliação, redução considerável do colesterol plasmático.

Jing e colaboradores ${ }^{69}$ avaliaram a importância clínica do uso de quitosana em pacientes com falência renal fazendo uso de hemodiálise. Após 12 semanas de ingestão de quitosana, o nível do colesterol sérico total passou de $10,14 \pm 4,40 \mathrm{mM}$ para 5,82 $\pm 2,19 \mathrm{mM}$.

\section{Redução de peso}

A redução de peso provocada pela administração de quitosana é objeto de discussão e polêmica na literatura. Existem trabalhos que atestam quitosana como notadamente capaz de reduzir peso em pessoas obesas sem necessidade de alteração na dieta alimen$\operatorname{tar}^{70,71}$. Entretanto, outras correntes sugerem que a redução, de fato, ocorre de forma mais acentuada quando a administração de quitosana é acompanhada de alteração nesta ${ }^{65,67,72-74}$. Muzzarelli55 sugere que este fato se deve a diferentes interesses entre pesquisa básica e aplicada, melhor dizendo, pesquisa feito pelo meio acadêmico, sem e com participação da indústria, pois, do ponto de 
vista industrial e capitalista, não é interessante qualquer tipo de restrição alimentar.

De acordo com Wadstein e colaboradores ${ }^{70}$, existem indivíduos que podem não responder ao tratamento, não se sabendo bem a razão para tal fato. Em estudo realizado por estes pesquisadores, de 332 voluntários submetidos ao ensaio, a maioria respondeu de forma satisfatória. Destes, 221 apresentaram redução de 4,1 kg durante 12 semanas, entretanto, 111 voluntários não responderam ao tratamento. O tipo de quitosana utilizada mostrou-se como variável importante na redução de peso. A pureza do polímero e seu tamanho particular podem influenciar significativamente esta propriedade. $\mathrm{O}$ biopolímero L $112^{\circledR}$, caracterizado por alto grau de pureza e tamanho de partículas adequado, apresentou os melhores resultados.

Embora não seja consenso no meio científico, quitosana é reconhecidamente segura e não-tóxica ao ser humano, podendose apontar que a dose utilizada em humanos é sempre menor que aquela utilizada em animais. A toxicidade da quitosana, $\mathrm{DL}_{50}$ de $16 \mathrm{~g} / \mathrm{kg} \mathrm{em}$ ratos $^{75}$, é evidenciada apenas quando esta é empregada como suplemento alimentar por longos períodos de tempo e está relacionada com o bloqueio da absorção de cálcio e vitaminas lipossolúveis, podendo acarretar disfunções ósseas, deficiência vitamínica e retardo do crescimento ${ }^{44}$. Assim sendo, não há risco de "overdose" ou alguma manifestação adversa, cabendo ressaltar que este polímero não é fármaco, mas, sim, substância natural notadamente capaz de promover a diminuição de peso em pessoas obesas ${ }^{55,74}$.

De acordo com Ventura ${ }^{74}$, dentre os mamíferos, o ser humano é exemplo raro em que quitinases específicas estão ausentes. Desta maneira, não é possível hidrolisar a quitosana de forma extensa, havendo apenas hidrólise parcial por bactérias da flora normal e hidrolases inespecíficas. Esta particularidade tem se mostrado como característica interessante, pois, na medida que o polímero é catiônico, este se encontra solúvel no estômago (faixa de $\mathrm{pH} 1$ -

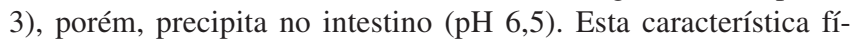
sico-química é o ponto chave no "mecanismo de ação" da quitosana, pois a mesma interfere na emulsificação de lipídeos no estômago e, ao chegar no intestino, devido à precipitação, o complexo não é absorvido.

Furda $^{71}$ realizou extenso trabalho para investigar este mecanismo de forma detalhada e estabeleceu que são pontos cruciais para o seu entendimento: viscosidade do polímero; interação iônica; interação com micelas mistas, ácidos biliares e ácidos graxos e inibição da lípase pancreática.

Fibras, em geral, sendo dotadas de viscosidade, possuem a habilidade de impedir a absorção de ácidos graxos e colesteróis. Isto ocorre por funcionarem como barreira física, impedindo a absorção destas substâncias ${ }^{76,77}$. No entanto, este não parece ser o ponto principal na ação da quitosana no tocante a tal aspecto. A quitosana é dotada de viscosidade, principalmente em meio ácido. Assim sendo, a ausência de viscosidade em local onde nutrientes são absorvidos, como o intestino, mostra que esta propriedade possui, apenas, caráter adjuvante. Entretanto, cabe ressaltar que o valor mínimo de viscosidade necessário para o aparecimento desta propriedade vai de 1,4 a 1,6 cP. Amostras de quitosana hidrolisadas (MM $5000 \mathrm{~g} / \mathrm{mol}$ ) e oligômeros com viscosidade inferior a 1,3 cP não apresentaram atividade hipocolesterolêmica e/ou hipolipidêmica. Os resultados mais promissores foram encontrados com amostras de quitosana cuja viscosidade estava entre 1,6 e $1,9 \mathrm{cP}$ e massa molecular entre $10^{4}-2 \times 10^{4} \mathrm{~g} / \mathrm{mol}^{17-80}$.

Outro aspecto a ser considerado é a interação iônica entre quitosana e sais biliares. Os primeiros trabalhos envolvendo a capacidade hipocolesterolêmica de quitosana sugerem este como sendo o mecanismo responsável pela diminuição do colesterol sérico $^{59,60,81,82}$. Esta interação ocorre entre a carga positiva presente na molécula da quitosana e a carga negativa presente em sais biliares e ácidos graxos. Desta maneira, pode ocorrer o comprometimento de estruturas micelares, inviabilizando a emulsificação de lipídeos e impedindo, conseqüentemente, que estes derivados sejam absorvidos. O resultado direto deste processo é o aumento na excreção de ácidos biliares e ácidos graxos nas fezes. Desta seqüência de eventos, resulta a oxidação compensatória de colesterol a sais biliares em nível hepático, visando, desta maneira, manter o "pool" de ácidos biliares, conduzindo, então, ao decréscimo do nível de colesterol sérico. A Figura 4 ilustra alguns dos mecanismos de ação da quitosana propostos para sua atividade hipocolesterolêmica e hipolipidêmica.
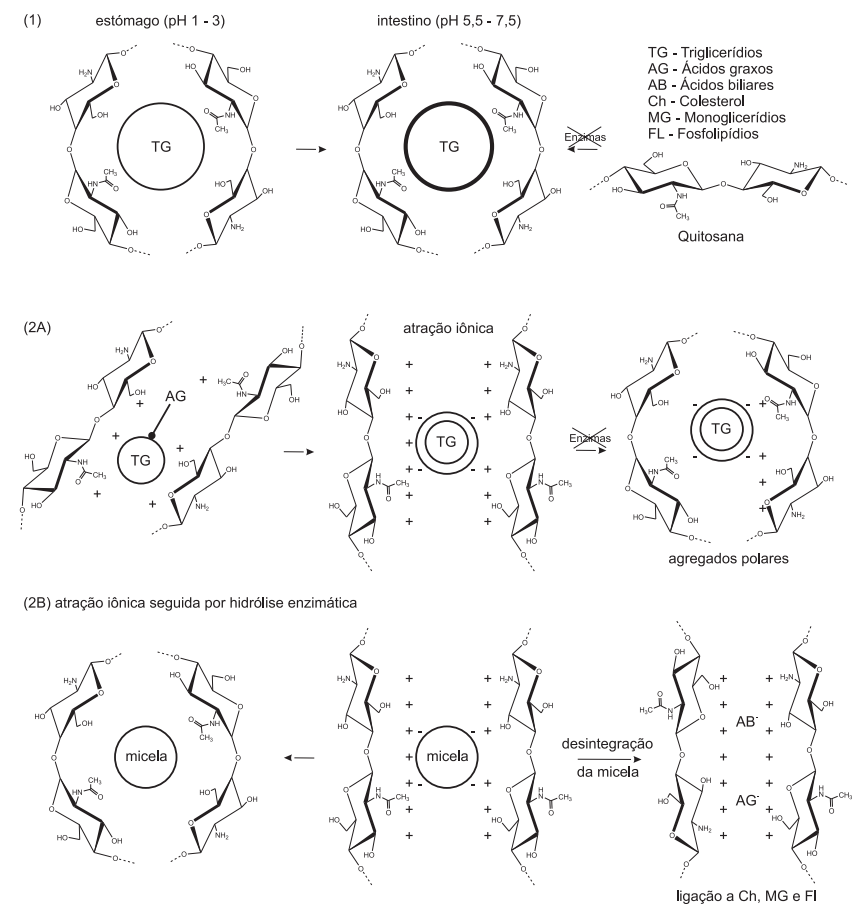

Figura 4. Prováveis mecanismos de ação de quitosana. Adaptado da ref. 55

\section{APLICAÇÕES}

A literatura atual é vasta em material sobre quitina e quitosana, podendo-se encontrar várias revisões que abordam diferentes aplicações destes polímeros e seus derivados ${ }^{54,65,83-85}$. Recentemente, três livros foram publicados ${ }^{10-12}$ e tratam da quitosana em várias linhas de pesquisas. No entanto, aspectos nos âmbitos farmacêutico e químico apresentam-se de forma marcante, podendo-se encontrar tópicos sobre preparação de membranas, sistemas de liberação de fármacos, uso como hipocolesterolêmico e, também, regeneração tecidual auxiliada por quitosana. Encontram-se aqui abordados alguns dos trabalhos mais recentes que envolvem quitosana e derivados.

\section{Latenciação e pró-fármacos de quitosana}

Latenciação é o processo que consiste na transformação do fármaco em forma de transporte inativo, que, in vivo, mediante reação química ou enzimática, libera a porção ativa no local de ação ou próximo dele ${ }^{86-91}$. Uma das formas latentes obtidas mediante este processo denomina-se pró-fármaco. Este é caracterizado pela ligação biorreversível entre o fármaco e outra molécula, denominada transportador (Figura 5). 


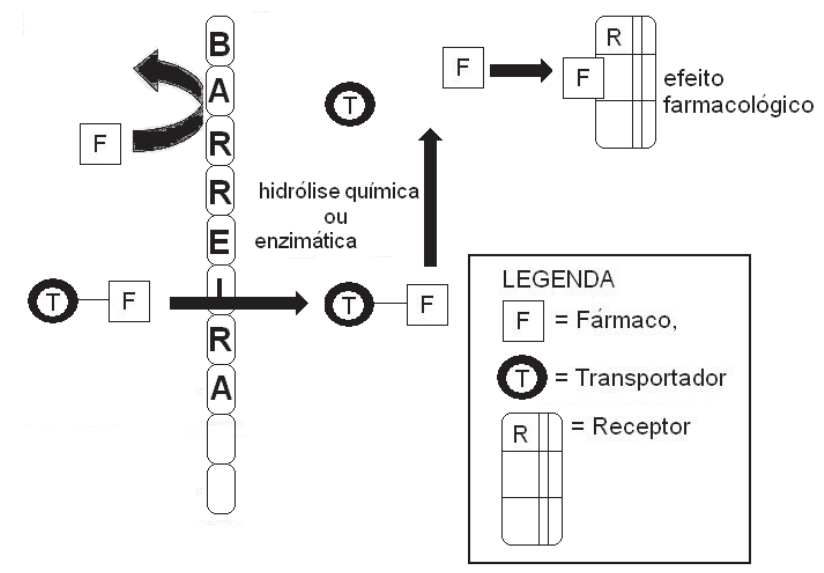

Figura 5. Representação esquemática do conceito de pró-fármaco. Adaptado da ref. 80

A latenciação tem sido bastante utilizada nos últimos anos para solucionar diversos problemas pertinentes a fármacos. Por meio deste processo, é possível obter: direcionamento de ação para sistema nervoso central (SNC) $)^{92,93}$, seletividade de ação $0^{94-96}$, prolongamento de ação $0^{97}$, melhoramento da biodisponiblidade ${ }^{98}$ e, ainda, resolução de problemas de instabilidade e baixa solubilidade em preparações farmacêuticas ${ }^{99,100}$.

Atualmente, existem na literatura exemplos importantes de prófármacos, que utilizam quitosana e derivados como transportadores poliméricos ${ }^{101-109}$. Estes polímeros têm se mostrado adequados, pois permitem diminuir ou resolver inconvenientes que determinados fármacos apresentam. Song e colaboradores ${ }^{102}$ conseguiram diminuir os efeitos adversos da mitomicina $\mathrm{C}$ empregando succinilquitosana e carboximetilquitina como transportadores.

Da mesma forma, utilizando mitomicina C, Kato e colaboradores ${ }^{107}$ empregaram succinilquitosana como transportador polimérico. Demonstrou-se que, de acordo com a metodologia empregada, se podem obter pró-fármacos de mitomicina $\mathrm{C}$ solúveis ou insolúveis em água. A cinética de liberação dos derivados insolúveis foi mais lenta e ambos os pró-fármacos exibiram propriedades antineoplásicas acompanhadas de diminuição de efeitos adversos em relação à administração do fármaco de forma isolada. Observou-se que a meia-vida pode variar de acordo com o grau de substituição do derivado. Aumento no grau de substituição implicou no aumento da meia-vida plasmática, explicando-se este fenômeno pela quantidade de carga negativa na molécula (grupo carboxilato), o que acarreta maior tempo de retenção do constituinte nos fluidos plasmáticos. Os pró-fármacos foram obtidos por condensação utilizando EDC (1-etil-3-(dimetilaminopropril) carbodiimida) e o $\mathrm{pH}$ foi mantido em 5 antes de se adicionar o fármaco. À medida que o pH aumentava, o grau de substituição da mitomicina C diminuía. A obtenção do pró-fármaco solúvel foi realizada utilizando-se éster glutárico do antineoplásico, visando evitar a formação de derivados insolúveis. A Figura 6 ilustra a metodologia para obtenção destes pró-fármacos.

Baba e colaboradores ${ }^{108}$ obtiveram pró-fármacos promissores da metanfetamina e carboximetilquitina. O pró-fármaco resultante mudou de forma satisfatória a cinética de liberação do fármaco. Anteriormente à latenciação, os níveis séricos eram mantidos por, no máximo, 7 h, e, após a obtenção da forma latente, foi possível obter níveis plasmáticos por até $120 \mathrm{~h}$. Este trabalho mostrou, também, a influência do espaçante utilizado em induzir ou não o aparecimento de reações imunogênicas. Evidenciou-se que espaçantes de maior cadeia alquílica induziam de forma mais acentuada as reações imunogênicas.

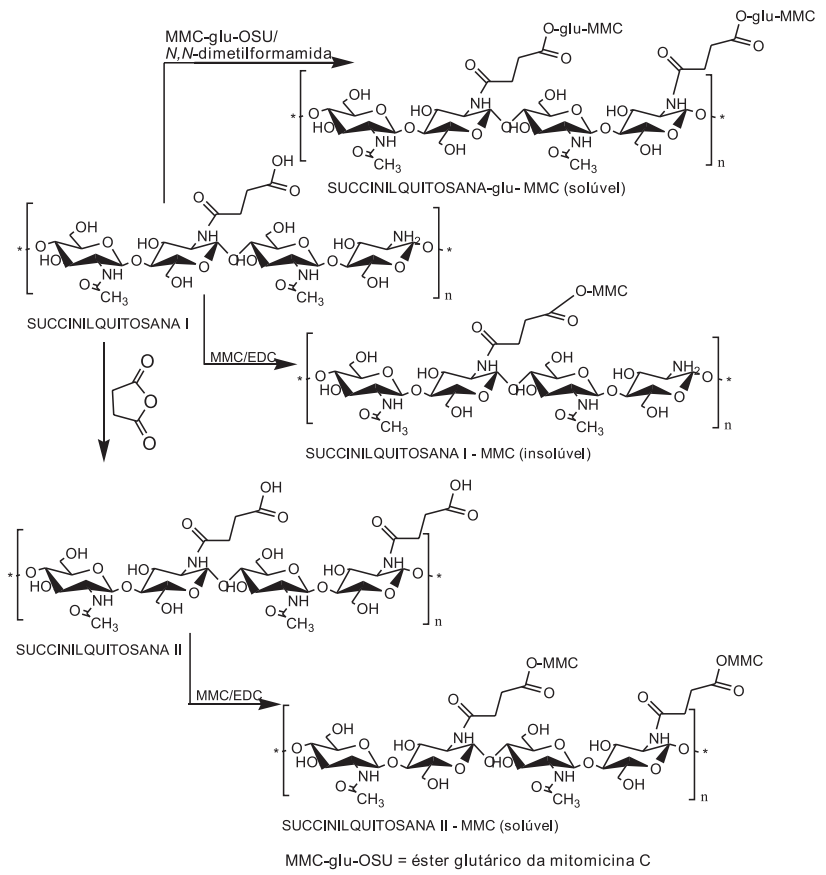

Figura 6. Esquema sintético para obtenção dos pró-farmacos de succinilquitosana e mitomicina $C$ solúveis e insolúveis em água. Adaptado da ref. 107

Ouchi e colaboradores ${ }^{109}$ conseguiram obter pró-fármacos de 5-fluorouracila, ativos em leucemia linfocítica induzida em ratos, utilizando carboximetilquitina e quitosana como transportadores. Além do prolongamento de ação, estes pró-fármacos exibiram menos efeitos adversos em relação aos que foram tratados somente com o fármaco. Este evento pode ser comprovado pela ausência de diminuição de peso, reação adversa presente nos ratos tratados apenas com o agente antineoplásico.

\section{Microesferas}

$\mathrm{O}$ uso de quitosana como transportador de fármacos tem permitido solucionar problemas como insolubilidade e hidrofobicidade de diversos agentes terapêuticos. No entanto, o caráter semicristalino destas preparações dificulta a compressão direta, tornando-se necessária a adição de agregantes para facilitar esta operação. Comprimidos para controle de peso com estearato de magnésio, que trazem consequiências negativas na eficácia da quitosana, constituem-se em exemplo dessa dificuldade ${ }^{110,111}$.

$\mathrm{O}$ desenvolvimento de microesferas pode diminuir este inconveniente, visto que estas são dotadas de cárater amorfo. Sua preparação pode ser feita de diversas maneiras, em que são considerados aspectos como hidrofilicidade, lipofilicidade e estabilidade térmica do fármaco em questão ${ }^{112}$.

Martinac e colaboradores ${ }^{113}$ realizaram estudo comparativo envolvendo genfibrozila na forma de pró-fármaco com PHEA (poliidroxietilaspartamida) e PHPA (poliidroxipropilaspartamida) como transportadores e microesferas contendo diferentes quantidades de quitosana. Ambos os sistemas, pró-fármacos e microesferas, promoveram alteração na cinética de liberação do fármaco. No entanto, os resultados mais promissores foram obtidos com microesferas constituídas de quitosana (baixa massa molar) combinada com PHPA ou HPMC (hidroxiproprilmetilcelulose) na proporção $(\mathrm{p} / \mathrm{p})$ de 2:1 ou 3:1 polímero/fármaco.

Cruz e colaboradores ${ }^{114}$ desenvolveram sistema de liberação para encapsular oxitetraciclina a partir de quitosana, polietileno- 
glicol e alginato. As micropartículas obtidas apresentaram diâmetro da ordem de 700 a $800 \mu \mathrm{m}$. O coeficiente de difusão do fármaco nos sistemas obtidos variou de acordo com o $\mathrm{pH}$ do meio: em meio ácido $(\mathrm{pH} \mathrm{1,2)} \mathrm{o} \mathrm{valor} \mathrm{determinado} \mathrm{foi} \mathrm{superior} \mathrm{àquele} \mathrm{encontrado}$ em meio neutro $(\mathrm{pH} \mathrm{7,4)}$.

\section{Liberação transdérmica}

A via transepitelial, em algumas situações, mais conhecida como transdérmica, apresenta uma série de vantagens em relação à via oral. As principais são ausência de biotransformação pré-sistêmica, o que aumenta a biodisponibilidade de fármacos, ausência de hidrólise enzimática ocorrida no trato gastrintestinal e diminuição de flutuações na concentração plasmática, que ocorrem, freqüentemente, quando se faz uso da via oral em horários diferentes ${ }^{115}$.

Existem, comercialmente, vários sistemas de liberação que utilizam a via transdérmica: Nicorette ${ }^{\circledR}$ Orthoevra $^{\circledast}$, Dentipach $^{\circledast}$, Estraderm $^{\circledast}$, Scopoderm $^{\circledR}$, Duragesic ${ }^{\circledR}$, entre outros ${ }^{85}$. Contudo, fármacos de natureza lipofílica são favoverecidos pelo uso desta metodologia, face à composição da membrana epitelial, limitando, por conseguinte, a utilização de tais sistemas para fármacos hidrofílicos. Quitosana e derivados, como por ex. $N$-trimetilquitosana, possuem propriedade fisico-química que os tornam adequados à resolução deste inconveniente. Os mesmos são capazes de agir como promotores de permeação de macromoléculas e compostos hidrofílicos, o que resulta em maior absorção destes agentes pela epiderme ou mucosas ${ }^{116-121}$.

Frente ao exposto, a utilização de quitosana em desenvolvimento de sistemas de liberação via trandérmica é, atualmente, alvo de muito interesse. A eficiência deste polímero em promover a penetração transepitelial tem sido demonstrada com vários agentes terapêuticos: insulina ${ }^{122,123}$, morfina ${ }^{124}$, heparina ${ }^{125}$ e hidrocortisona $^{126}$. Illum e colaboradores ${ }^{124}$ verificaram o sucesso desta metodologia em fase I, na qual se utilizaram voluntários sadios para averiguar a eficácia terapêutica do fármaco.

Quando se pretende desenvolver sistemas de liberação utilizando a via transdérmica, deseja-se obter liberação do fármaco da matriz polimérica de forma contínua, sem, no entanto, atingir níveis tóxicos, e mais ainda, de maneira que não danifique as células da membrana epitelial. Fang e colaboradores ${ }^{127}$ demonstraram, claramente, que quitosana atende esta especificação, pois 35 min após a retirada do adesivo, a pele retornou à condição inicial.

O mecanismo pelo qual a quitosana aumenta a absorção dos fármacos e macromoléculas permanece desconhecido. No entanto, dois aspectos estão associados a esta propriedade. Primeiramente, creditase importância ao seu efeito oclusor em nível da pele, aumentando, desta maneira, a hidratação e facilitando a absorção. Segundo, e não menos importante, seria sua ação no nível das junções intercelulares, como se "abrisse" caminho para passagem da molécula ${ }^{85}$. A Figura 7 ilustra, de forma esquemática, as junções intercelulares antes e depois do tratamento com glutamato de quitosana.

\section{Complexos de quitosana e DNA, transfecção e desenvolvimento de vacinas}

O uso de sistemas coloidais como transportadores de fármacos, proteínas, antígenos e genes tem sido amplamente descrito na literatura. Este interesse ocorre, principalmente, devido à sua baixa toxicidade e, em alguns casos, ao sinergismo no efeito terapêuti$\mathrm{co}^{128,129}$. A utilização de vírus atenuado continua sendo a principal metodologia de desenvolvimento de vacinas, cerca de $80 \%{ }^{130}$. Entretanto, estes sistemas apresentam limitações, dentre elas, o aparecimento de inconvenientes imunológicos e propriedades
Ausência de glutamato de quitosana

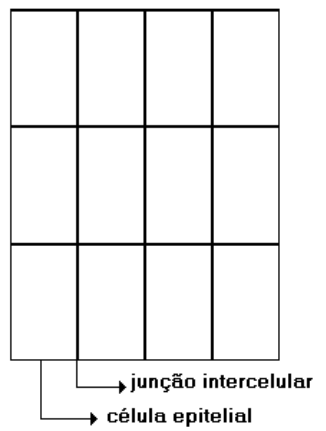

Presença de glutamato de quitosana

Figura 7. Representação esquemática das junções intercelulares antes $(A) e$ depois (B) do tratamento com glutamato de quitosana. Adaptado da ref. 85

oncongênicas ${ }^{131-133}$. Para resolver este problema, a quitosana tem sido utilizada como transportador de DNA e o processo de transfecção foi obtido com elevados percentuais de eficiência ${ }^{134-137}$.

A eficiência da transfecção pode ser avaliada em função da quantidade de DNA que se consegue inserir na célula, em qualquer sistema de liberação. Estudos descrevem com detalhes este mecanismo complexo entre DNA e quitosana ${ }^{138,139}$. O tamanho exato da estrutura micelar e sua distribuição são dois parâmetros importantes que determinam a eficiência da transfecção. Kim e colaboradores ${ }^{140}$ estudaram estes aspectos com quitosana modificada por inserção de ácido desoxicólico. O polissacarídeo foi inicialmente despolimerizado com nitrito de sódio e, em seguida, conjugado ao ácido desoxicólico usando EDC (1-etil-3-(dimetilaminopropril) carbodiimida). Os agregados obtidos variaram entre 130-300 nm de diâmetro, sendo esta medida dependente da massa molar da quitosana utilizada. Yevdokimov e colaboradores ${ }^{141}$ também investigaram a formação de complexos entre DNA e quitosana. Este grupo estudou os parâmetros que influenciam o processo de transfecção, que são, em particular, a influência do pH do meio, massa molecular da quitosana, força iônica e distância entre grupamentos amínicos presentes na molécula do polissacarídeo. A maior eficiência na transfecção foi obtida em pH 6,8, que corresponde ao pKa dos grupamentos amínicos da quitosana avaliada. Desta maneira, a quitosana está suficientemente ionizada e pode interagir com a carga negativa do grupo fosfato do DNA da melhor forma, resultando, por conseguinte, em altos níveis de complexação.

Iqbal e colaboradores ${ }^{142}$ realizaram extenso trabalho para investigar a liberação de DNA a partir do complexo DNA-quitosana, sendo escolhida a via nasal. A principal vantagem desta via é a menor quantidade de antígeno necessária, se comparada à imunização via oral. Observou-se que esta metodologia foi capaz de induzir o aparecimento de anticorpos de forma significativa, resultando em decréscimo da carga viral do VSR (vírus sincial respiratório). O tamanho das partículas obtidas ficou entre 300 e $330 \mathrm{~nm}$ e o potencial zeta em água, entre 37 e $40 \mathrm{mV}$. De posse destas medidas, os autores afirmaram que este sistema representa importante estratégia no desenvolvimento de vacinas. A Figura 8 ilustra as etapas envolvidas na liberação do plasmídeo de conjugado ou matriz polimérica.

Mohapatra $^{143}$ também avaliou o uso de quitosana como matriz de liberação de DNA visando o desenvolvimento de vacinas. O uso de nanosferas de DNA-quitosana administradas via nasal mostrouse adequado e foi capaz de diminuir de forma significativa o título viral em infecção respiratória causada pelo VSR.

Okamoto e colaboradores ${ }^{144}$ relataram o uso destes sistemas em infecção causada pelo citomegalovírus e verificaram a liberação de DNA a partir do complexo em nível pulmonar. O complexo 


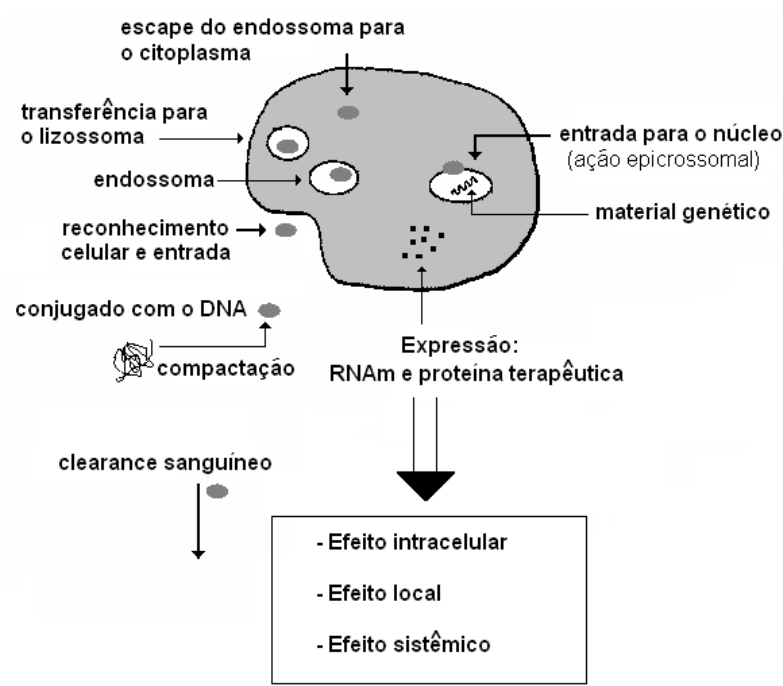

Figura 8. Etapas envolvidas na liberação do plasmídeo. Adaptado da ref. 139

DNA-quitosana foi preparado com dióxido de carbono supercrítico e a atividade biológica, determinada pelo ensaio da luciferase.

\section{Membrana assimétricas de DNA e quitosana}

Quando se desenvolvem membranas de quitosanas com pretensão de usá-las com finalidade cirúrgica, deve-se ter claro que este curativo deve interagir apenas com o tecido lesionado. As membranas de quitosana, comuns não atendem a este pré-requisito, pois, como suas superficies superior e inferior são semelhantes, estas aderem de forma igual aos tecidos lesionado e sadio. Uma forma de solucionar este inconveniente é a utilização de membranas assimétricas, caracterizadas por superfícies diferentes, de forma que é alcançada apenas a adesão ao tecido lesionado ${ }^{145}$.

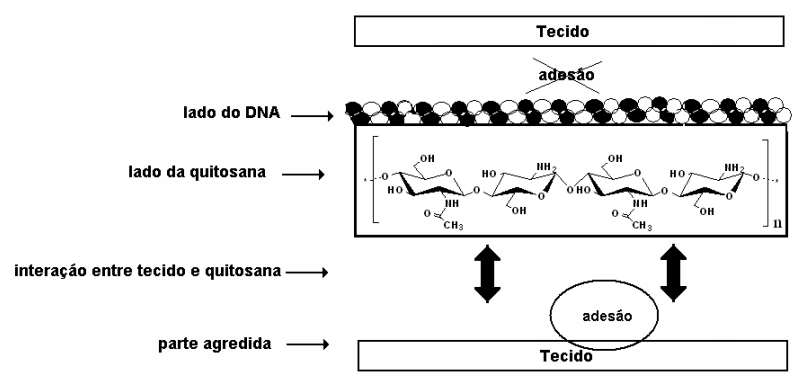

Figura 9. Modelo de membrana assimétrica. Adaptado da ref. 145

Rikimaru e colaboradores ${ }^{145}$ desenvolveram membrana assimétrica utilizando camada de DNA como superfície (Figura 9). Primeiramente, é obtida a membrana de quitosana comum e, depois, insere-se uma camada de DNA nesta. Analisando-se as propriedades mecânicas, pode-se evidenciar que estas membranas são adequadas ao uso como curativo cirúrgico.

\section{CONCLUSÃO E PERSPECTIVAS}

Características como biocompatibilidade, biodegradabilidade e perfil atóxico fazem da quitosana excelente material a ser explorado como veículo de preparações cosméticas e farmacêuticas. As propriedades biológicas, peculiares à quitosana e explicadas, muitas vezes, pelo grupamento amínico livre e suscetível de protonoção das unidades desacetiladas do polímero, abrem grande leque de aplicações, que vão desde simples veículo até a exploração farmacológica de suas atividades antimicrobiana, coagulante, hipocolesterolêmica, regeneradora em osteoartrite, dentre outras. Além disso, corrobora o fato de ser material obtido, principalmente, do exosqueleto de crustáceos, abundante em áreas de costa marítima e que tem, na produção da quitosana, sua reciclagem com viabilidade econômica e ecológica.

Tendo em vista o que foi exposto, considera-se que o interesse no emprego da quitosana por suas mais variadas propriedades será aumentado, sobremaneira, no futuro, permitindo que estudos mais aprofundados conduzam a novas aplicações de importância.

\section{AGRADECIMENTOS}

Ao CNPq e à CAPES, pela concessão das bolsas de doutorado e de estágio de doutorado no exterior, respectivamente, ambas concedidas a H.S.R. Costa Silva e K.S.C.R. dos Santos. Ao Prof. R. A. A. Muzzarelli, por todo empenho, fornecimento de bibliografia e ajuda valiosa durante o início do estágio sanduíche na Universidade Politécnica de Marche, Ancona, Itália.

\section{REFERÊNCIAS}

1. Kubota, N.; Tastumoto, N.; Sano, T.; Toya, K.; Carbohydr. Res. 2000, 324, 268.

2. Kafetzoulos, D.; Martinov, A.; Bouriotis, V. Em Chitin Enzymology; Muzzarelli, R. A. A., ed., European Chitin Soc: Ancona, 1993, p. 147.

3. Singla, A. K.; Chawla, M.; J. Pharm. Pharmacol. 2001, 53, 1047.

4. Le Dung, P.; Milas, M.; Rinaudo, M.; Desbrières, J.; Carbohydr. Polym. 1994, 24, 209.

5. Skjak-Braek, G.; Anthonsen, T.; Sandford, P., eds.; Chitin and Chitosan: sources, chemistry, biochemistry, physical properties and applications, Elsevier Applied Science: London, 1989.

6. Brine, C. J.; Sandford, P. A.; Zikakis, J. P., eds.; Advances in chitin and chitosan, Elsevier Applied Science: London, 1992.

7. Muzzarelli, R. A. A., ed.; Chitin Enzymology, European Chitin Society: Ancona, 1993, vol. I.

8. Muzzarelli, R. A. A., ed.; Chitin Enzymology, Atec: Grottammare, 1996, vol. II.

9. Goosen, M.F.A., ed.; Applications of chitin and chitosans, Lancaster: Pensylvania, 1997.

10. Muzzarelli, R. A. A., ed.; Chitosan per or: from dietary supplement to drug carrier, Atec: Grottammare, 2000.

11. Muzzarelli, R. A. A., ed.; Chitin Enzymology, Atec: Grottammare, 2001, vol. III.

12. Muzzarelli, R. A. A.; Muzzarelli, C., eds.; Chitosan in pharmacy and chemistry, Atec: Grottammare, 2002.

13. Nakatsuta, S.; Andrady, A. L.; J. Appl. Polym. Sci. 1992, 44, 17.

14. Kubota, N.; Kikuchi, Y.; Mizuhara, Y.; Ishihara, T.; Takita, Y.; J Appl. Polym. Sci. 1993, 50, 1665 .

15. Phaechamud, T.; Koizumi, T.; Ritthidej, G. C.; Int. J. Pharm. 2000, 198, 97.

16. Ginani, M. F.; Navarro, M. V.; do Nascimento, E. G.; de Oliveira, U. O. B.; Quim. Nova 1999, 22, 801.

17. Tonhi, E.; Plepis, A. M. G.; Quim. Nova 2002, 25, 943

18. Khor, E.; Curr. Opin. Solid State and Materials Science 2002, 6, 313.

19. Muzzarelli, R. A. A.; Tosi, G.; Francesgangeli, O.; Muzzarelli, C.; Carbohydr. Res. 2003, 338, 2247.

20. Muzzarelli, C.; Vesna, S.; Gobbi, L.; Tosi, G.; Muzzarelli, R. A. A.; Carbohydr. Polym. 2004, 57, 73.

21. Shigemasa, Y.; Usui, H.; Morimoto, M.; Saimoto, H.; Okamoto,Y. ; Minami, S.; Sashina, H.; Carbohydr. Polym. 1999, 39, 237.

22. Jia, Z.; Shen, D.; Xu, W.; Carbohydr. Res. 2001, 333, 1.

23. Xie, W.; Xu, P.; Liu, Q.; Bioorg. Med. Chem. Lett. 2001, 11, 1699.

24. Baumann, H.; Faust, V.; Carbohydr. Res. 2001, 331, 43.

25. Sashiwa, H.; Shigemasa, Y.; Carbohydr. Polym. 1999, 39, 127.

26. Heras, A.; Rodriguez, N. M.; Ramos, V. M.; Agullo, E.; Carbohydr. Polym. 2001, 44, 1 .

27. Ramos, V. M.; Rodríguez, N. M.; Rodríguez, M. S.; Heras, A.; Agulló, E.; Carbohydr. Polym. 2003, 51, 425.

28. Ramos, V. M.; Rodríguez, N. M.; Díaz, M. F.; Rodríguez, M. S.; Heras, A.; Agulló, E.; Carbohydr. Polym. 2003, 52, 39. 
29. Hirano, S.; Moriyasu,T.; Carbohydr. Res. 1981, 92, 319.

30. Yamagushi, R.; Arai, Y.; Itoh, T.; Hirano, S.; Carbohydr. Res. 1981, 88, 172.

31. Hirano, S.; Hayaki, K.; Hirochi, K.; Carbohydr. Res. 1992, 225, 175.

32. Piza, F. A. T.; Siloto, A. P.; Carvalho, C. V.; Franco, T. T.; Braz. J. Chem. Eng. 1999, 16, 85

33. Muzzarelli, R.; Wecky, M.; Filippini, O.; Lough, C.; Carbohydr. Polym. 1989, 11, 307

34. Rinauldo, M.; Desbriéres, J.; Le Dung, P.; Thuy Binh, P.; Dong, N. T.; Carbohydr. Polym. 2001, 46, 339.

35. Costa Silva, H. S. R.; Dos Santos, K. S. C. R.; Fagundes, F. P.; Garcia, R. B.; Ferreira, E. I.; Revista Brasileira de Ciências Farmacêuticas 2003, 39, supl. 3, 87.

36. dos Santos, K. S. C. R.; Costa Silva, H. S. R.; Ferreira, E. I.; Livro de Resumos da $26^{a}$ Reunião da Sociedade Brasileira de Química, Poços de Caldas, Brasil, 2003.

37. Canella, K. M. N. D.; Garcia, R. B.; Quim. Nova 2001, 24, 13.

38. Dos Santos, K. S. C. R.; Costa Silva, H. S. R.; Ferreira, E. I.; Bruns, R.; Carbohydr. Polym. 2005, 59, 37.

39. Ravi Kumar, M. N. V.; React. Funct. Polym. 2000, 46, 1.

40. Olsen, R.; Schwartzmiller, D.; Weppner, W.; Winandy, R. Em ref. 5, p. 813.

41. Seo, H.; Mitsuhashi, K.; Tanibe, H. Em ref. 6, p. 34.

42. Koide, S. S.; Nutr. Res. 1998, 18, 1091.

43. Lifeng, Q.; Zirong, Xu.; Jiang, X.; Zou, X.; Carbohydr. Res. 2004, 339, 2693.

44. Zheng, L-Y.; Zhu, J.-F.; Carbohydr. Polym. 2003, 54, 527.

45. Rao, S. B.; Sharma, C. P.; J. Biomed. Mater. Res., Part A 1997, 34, 21.

46. Okamoto, Y.; Yano, R.; Miytake, K.; Tomohiro, I.; Shigemasa, Y.; Minami, S.; Carbohydr. Polym. 2003, 53, 337.

47. Okamoto, Y.; Kawakami, K.; Miyatake, K.; Morimoto, M.; Shigemasa, Y.; Minami, S.; Carbohydr. Polym. 2002, 49, 249.

48. Insel, P. A. Em As bases farmacológicas da terapêutica, $9^{\mathrm{a}}$ ed.; Hardman, J. G.; Limbird, L. E.; Molinoff, P. B.; Ruddon, R. W.; Gilman, A. G.; eds.; McGraw-Hill: México, 1996, p. 450.

49. Muzzarelli, R. A. A. Em ref. 6, p. 25.

50. Muzzarelli, R. A. A.; Cell. Mol. Life Sci. 1997, 53, 131.

51. Sandford, P. A. Em ref. 5, p. 51.

52. Kifune, K. Em ref. 5, p. 9.

53. Goldeberg, S. H.; Von Feldt, J. M.; Lonner, J. H.; Am. J. Orthopedics 2001, $12,673$.

54. Gracy, R. W.; Agro Food Industry Hi-Tech. 2003, 14, 53

55. Muzzarelli, R. A. A. Em ref. 10, p. 3.

56. Deal, C. L.; Moskovitz, R. W.; Rheumatic Disease Clinics of North America 1999, 25, 379.

57. Talent, J. M.; Gracy, R. W.; Clinical Therapeutics 1996, 18, 1184

58. Stenikat, I.; Palumbo, R.; Canali, S.; Zanolo, G.; Arnzeim. Forsch. 1993, $43,1109$.

59. Sugano, M.; Fujikawa, T.; Hiratsuji, Y.; Hasegawa, Y.; Nutrition Reports International 1978, 18, 531 .

60. Kobayashi, T.; Otsuka, S.; Yugari, Y.; Nutrition Reports International 1979, $19,327$.

61. Ormrod, D. J.; Holmes, C. C.; Miller, T. E.; Atherosclerosis 1998, 138, 329.

62. Okamoto, D. J.; Nose, M.; Sashiwa, H.; Morimoto, M.; Saimoto, H.; Shigemasa, Y.; Minami, S. Em Advances in chitin sciences; Domard, A.; Roberts, G. A. F.; Varum, K. M., eds.; Jacques Andrè Publisher: Lyon France, 1997, vol. II, p. 625.

63. Miura, T.; Usami, M.; Tsura, Y.; Ishida, H.; Seino, Y.; Biol. Pharm. Bull. 1995, 18, 1623.

64. Maezaki, Y.; Keisuki, T.; Nakagawa, Y.; Kawai, Y.; Akimoto, M.; Tsugita, T.; Takekawa, W.; Terada, A.; Hara, H.; Mitsuoka, T.; Biosci., Biotechnol., Biochem. 1993, 57, 1439.

65. Pittler, M. H.; Abbot, N. C.; Harckness, E. F.; Ernst, E.; Eur. J. Clinical Nutrition 1999, 53, 379 .

66. Gallaher, D. D.; Agro Food Industry Hi-Tech. 2003, 14, 32.

67. Wuolijoki, E.; Hirvela, T.; Ylitalo, P.; Methods and Findings in Experimental and Clinical Pharmacology 1999, 21, 357.

68. Bokura, H.; Kobayashi, S.; Eur. J. Clinical Nutrition 2003, 57, 721.

69. Jing, S. B.; Li, L.; Ji, D.; Takigushi, Y.; Yamagushi, T.; J. Pharm. Pharmacol. 1997, 49, 721.

70. Wadstein, J.; Thom, E.; Heldman, E.; Gudmunsson, S.; Lilja, B. Em ref. 10, p. 65.

71. Furda, I. Em ref. 10, p. 41

72. Veneroni, G.; Veneroni, F.; Contos, S.; Tripodi, S.; De Benardi, M.; Guarino, C.; Marletta, M. Em ref. 8, p. 63.

73. Veneroni, G.; Veneroni, F.; Contos, S.; Tripodi, S.; De Benardi, M.; Guarino, C.; Marletta, M.; Acta Toxicologica et Therapeutica 1996, 17, 53.

74. Ventura, P. Em ref. 8, p. 55.
75. Hirano, S. Em ref. 5, p. 37.

76. Vahouny, G. V.; Federation Proceedings 1982, 41, 2801.

77. Ikeda, I.; Tomari, Y.; Sugano, M.; J. Nutr. 1989, 119, 1383

78. Ikeda, I.; Sugano, M.; Yoshida, K.; Sasaki, E.; Iwamoto, Y.; Hatano, K.; J. Agric. Food Chem. 1993, 41, 431.

79. Sugano, M.; Watanabe, S.; Kishi, A.; Izume, M.; Ohtakara, A.; Lipids 1988, 23, 187.

80. Sugano, M.; Yoshida, K.; Hashimoto, M.; Enomoto, K.; Hirano, S. Em ref. 6, p. 472.

81. Nagyvary, J. J.; Falk, J. D.; Hill, M. L.; Schimidt, M. L.; Wilkins, A. K.; Bradbury, E. L.; Nutrition Reports International 1979, $20,677$.

82. Sugano, M.; Fujikawa, T.; Hiratsuji, Y.; Nakashima, K.; Fukuda, N.; Hasegawa, Y.; Am. J. Clin. Nutr. 1980, 33, 787.

83. Muzzarelli, C.; Muzzarelli, R. A. A.; Agro Food Industry Hi-Tech. 2003, 14,30 .

84. Muzzarelli, C.; Muzzarelli, R. A. A.; Agro Food Industry Hi-Tech. 2003, $14,39$.

85. Smith. J. M.; Wood, E. J.; Agro Food Industry Hi-Tech. 2003, 14, 46

86. Korolkovas, A.; Essentials of medicinal chemistry, $2^{\text {nd }}$ ed., WileyInterscience: New York, 1988.

87. Friis, G. J.; Bundgaard, H. Em A text book of drug design and development, $2^{\text {nd }}$ ed.; Krogsgaard-Larsen, P.; Lijefor, T.; Madsen, U., eds.; Harwood Academic Publishers: Amsterdam, 1996, p. 352.

88. Chung, M. C.; Ferreira, E. I.; Quim. Nova 1999, 22, 75.

89. Wermuth, C. G. Em The practice of medicinal chemistry, $2^{\text {nd }}$ ed.; Wermuth, C. G., ed.; Academic Press: London, 2003, p. 561

90. Testa, B., Biochem. Pharmacol. 2004, 68, 2097.

91. Ettmayer, P.; Amidon, G. L.; Clement, B.; Testa, B.; J. Med. Chem. 2004, 47, 2393.

92. Somogyi, G.; Nishitani, S.; Nomi, D.; Buchwald, P.; Prokai, L.; Bodor, N.; Int. J. Pharm. 1998, 166, 15.

93. Somogyi, G.; Buchwald, P.; Bodor, N.; Pharmazie 2002, 57, 135.

94. Matsumoto, H.; Sohma, Y.; Kimura, T.; Hayashi, Y.; Kiso, Y.; Bioorg. Med. Chem. Lett. 2001, 11, 605

95. Bielawska, A.; Chrzanowski, K.; Bielawska, K.; Palka, J.; Pharmazie 2001, $56,290$.

96. Garky, V. M.; Lumma, P. K.; Feng, D-M.; Wai, J.; Ramjit, h. G.; Sardana, M. K.; Oliff, A.; Raymond, E. J.; Jones, D. D.; Freidinger, R. M.; J. Med. Chem. 2001, 44, 4216.

97. Kawakami, S.; Nishida, K.; Mukai, T.; Yamamura, K.; Nakamura, J.; Sakaeda, T.; Nakashima, M.; Sasaki, H.; J. Controlled Release 2001, 76 , 255.

98. Mori, N.; Kodama, T.; Sakai, A.; Suzuki, T.; Suguhara, T.; Yamagushi, S.; Nishijima, T.; Aoki, A.; Toriya, M.; Kasai, M.; Hatano, S.; Kitagawa, M.; Yoshimini, A.; Nishimura, K.; Int. J. Antimicrob. Agents 2001, 18, 451.

99. Yamagushi, T.; Naoyuki, H.; Kunihiko, O.; Hiroaki, A.; Kouji, O.; Noriyuki, N.; Bioorg. Med. Chem. Lett. 1999, 9, 1639.

100. Badawy, F. I. S.; Int. J. Pharm. 2001, 223, 81

101. Song, Y.; Onishi, H.; Nagai, T.; Chem. Pharm. Bull. 1992, 40, 2822.

102. Song, Y.; Onishi, H.; Machida, Y.; Nagai, T.; Biol. Pharm. Bull. 1993, 16, 48 .

103. Song, Y.; Onishi, H.; Machida, Y.; Nagai, T.; J. Controlled Release 1996, 42, 93.

104. Sato, M.; Onishi, H.; Takaraha, J.; Machida, Y.; Biol. Pharm. Bull. 1996. 19,1170

105. Kato, Y.; Onishi, H.; Machida, Y.; STP Pharma Sciences 2000, 10, 133

106. Kato, Y.; Onishi, H.; Machida, Y.; Int. J. Pharm. 2001, 226, 93.

107. Kato, Y.; Onishi, H.; Machida, Y.; Biomaterials 2004, 25, 907.

108. Baba, S.; Uraki, Y.; Miura, Y.; Tokura, S. Em ref. 5, p. 703.

109. Ouchi, T.; Inosaka, K.; Banba, T.; Ohya, Y. Em ref. 6, p. 106

110. Knapczyk, J.; Int. J. Pharm. 1993, 89, 1.

111. Rege, P. R.; Shukla, D. J.; Block, L. H.; Int. J. Pharm. 1999, 181, 49.

112. Sinha, V. R.; Singla, A. K.; Wadhawan, S.; Kaushik, R.; Kumria, R.; Bansal, K. Dhawan, S.; Int J. Pharm. 2004, 274, 1

113. Martinac, A.; Filipovic-Grcic, J.; Barbaric, M.; Zorc, B.; Voinovich, D.; Jalsenjak, I.; Eur. J. Pharm. Sci. 2002, 17, 207.

114. Cruz, M. C. P.; Ravagnani, S. P.; Brogna, F. M. S.; Campana, S. P.; Trivino, G. C.; Lisboa, A. C. L.; Mei, L. H. I.; Biotechnol. Appl. Biochem. 2004, $40,243$.

115. Washington, N.; Washington, C.; Wilson, C. Em Physiological pharmaceutics barriers to drug absorption, $2^{\text {nd }}$ ed.; Washington, N.; Washington, C.; Wilson, C., eds.; Taylor and Francis: London, 2001, p. 181.

116. Thanou, M.; Verhoef, J. C.; Kotzé, A. F.; Junginger, H. E. Em ref. 10, p. 97.

117. Hamman, J. H.; Kotzé, A. F. Em ref. 12, p. 41.

118. Kotzé, A. F.; Hamman, J. H.; Snyman, D.; Jonker, C.; Stander, M. Em ref. 12 , p. 31. 
119. Portero, A.; Alonso, M. J.; Remunan-Lopez, C. Em ref. 12, p. 21.

120. Senel, S.; Kremer, M. J.; Wertz, P. W.; Hill, J. R.; Kas, S.; Hincal, A. A.; Squier, C. A. Em ref. 12, p. 77.

121. Verhoef, J. C.; Thanou, M.; Verheijden, J. H. M.; Junginger, H. E. Em ref. 12, p. 51.

122. Illum, L.; Farraj, N.; Davis, S.; Pharm. Res. 1994, 11, 1186.

123. Aspden, T.; Illum, L.; Skaugrud, O.; Eur. J. Pharm. Sci. 1996, 4, 23.

124. Illum, L.; Watts, P.; Fisher, A.; Hinchcliffe, M.; Norbury, H.; Jabbalgill, I.; Nankervis, R.; Davis, S.; J. Pharmacol. Exp. Ther. 2002, 301, 391.

125. Thanou, M.; Nihot, M.; Jansen, M.; Verhoef, J.; Jungiger, H.; J. Pharm. Sci. 2001, 90, 38.

126. Senel, S.; Hincal, A.; J. Controlled Release 2001, 72, 133.

127. Fang, L.; Leu, Y.; Wang, Y.; Tsai, T.; Eur. J. Pharm. Sci. 2002, 15, 417.

128. Kreuter, J. Em Colloidal drug delivery systems systems; Kreuter, J., ed.; Marcel Dekker: New York, 1994, p. 219.

129. Stolnik, S.; Illum, L.; Davis, S. S.; Adv. Drug Delivery Rev. 1995, 16, 195.

130. Wivel, N. A.; Wilson, J. M.; Hematology/Oncology Clinics of North America 1998, 12, 483.

131. Mulligan, R. C.; Science 1993, 260, 926.

132. Verma, I. M.; Somia, N.; Nature 1997, 389, 239.

133. Anderson, W. F.; Nature 1998, 392 (suppl.), 25.
134. Erbacher, P.; Zou, S.; Bettinger, T.; Steffan, A. M.; Remy, J. S.; Pharm. Res. 1998, 15, 1332.

135. Leong, K. W.; Mao, H, Q.; Truong-Le, V. L.; Roy, K.; Walsh, J. T.; August, J. T.; J. Controlled Release 1998, 53, 183.

136. Venkateshi, S.; Smith, T. J.; Biotechnol. Appl. Biochem. 1998, 27, 265.

137. Richardson, S. C. W.; Kolbe, H. V. J.; Duncan, R.; Int. J. Pharm. 1999, $178,231$.

138. Ishii, T.; Okahata, Y.; Sato, T.; Biochim. Biophys. Acta 2001, 1514, 51.

139. Davis, S. S.; Illum, L. Em ref. 10, p. 137.

140. Kim, Y. H.; Gihm, S. H.; Park, C. R.; Bioconjugate Chem. 2001, 12, 932.

141. Yevdokimov, Y. M.; Salyanov, V. I.; Semenov, S. V.; Il'ina, A. V.; Varlamov, V. P.; Mol. Biol. 2002, 36, 419.

142. Iqbal, M.; Lin, W.; Jabbal-Gill, I.; Davis, S. S.; Steward, M. W.; Illum, L.; Vaccine 2003, 21, 1478.

143. Mohapatra, S. S.; Pediatric Infectious Diseases Journal 2003, 22, suppl. 2,100 .

144. Okamoto, H.; Nishida, S.; Todo, H.; Sakakura, Y.; Lida, K.; Danjo, K.; J. Pharm. Sci. 2003, 92, 371.

145. Rikimaru, S.; Wakabayashi, Y.; Nomizu, M.; Nishi, N.; Polym. J. 2003, 35, 255. 